\title{
Out of the silos: identifying cross-cutting features of health-related stigma to advance measurement and intervention
}

\author{
Wim H. van Brakel ${ }^{1 *}$ (D, Janine Cataldo², Sandeep Grover ${ }^{3}$, Brandon A. Kohrt ${ }^{4}$, Laura Nyblade ${ }^{5}$, Melissa Stockton ${ }^{6}$,
} Edwin Wouters ${ }^{7,8}$ and Lawrence H. Yang 9,10

\begin{abstract}
Background: Many health conditions perceived to be contagious, dangerous or incurable, or resulting in clearly visible signs, share a common attribute - an association with stigma and discrimination. While the etiology of stigma may differ between conditions and, sometimes, cultural settings, the manifestations and psychosocial consequences of stigma and discrimination are remarkably similar. However, the vast majority of studies measuring stigma or addressing stigma through interventions employ a disease-specific approach.

Main body: The current paper opposes this siloed approach and advocates a generic concept of 'health-related stigma' in both stigma measurement and stigma interventions. Employing a conceptual model adapted from Weiss, the current paper demonstrates the commonalities among several major stigmatized conditions by examining how several stigma measurement instruments, such as the Social Distance Scale, Explanatory Model Interview Catalogue, Internalized Stigma of Mental Illness, and Berger stigma scale, and stigma reduction interventions, such as information-based approaches, contact with affected persons, (peer) counselling, and skills building and empowerment, were used successfully across a variety of conditions to measure or address stigma. The results demonstrate that 'health-related stigma' is a viable concept with clearly identifiable characteristics that are similar across a variety of stigmatized health conditions in very diverse cultures.
\end{abstract}

Conclusion: A more generic approach to the study of health-related stigma opens up important practical opportunities - cross-cutting measurement and intervention tools are resource saving and easier to use for personnel working with multiple conditions, allow for comparison between conditions, and recognize the intersectionality of many types of stigma. Further research is needed to build additional evidence demonstrating the advantages and effectiveness of cross-condition approaches to stigma measurement and interventions.

Keywords: Health-related stigma, measurement, interventions, cross-cutting approaches, HIV, mental health, leprosy, tuberculosis, neglected tropical diseases, disabilities

\section{Background}

Many health conditions perceived to be contagious, dangerous or incurable, to result in clearly visible signs, or to be caused by breaking taboos or immoral behavior share a common attribute - an association with stigma and discrimination. These health conditions are diverse in nature and include infectious diseases like HIV, tuberculosis (TB), leprosy and lymphatic filariasis,

\footnotetext{
* Correspondence: w.v.brakel@leprastichting.nl

${ }^{1}$ NLR, Wibautstraat 137k, 1097DN Amsterdam, Netherlands

Full list of author information is available at the end of the article
}

non-infectious chronic conditions such as epilepsy and cancers, and mental health conditions such as schizophrenia, depression, and substance abuse. Jones et al. [1] proposed six features, namely, (1) esthetics, (2) concealability, (3) course, (4) disruptiveness, (5) origin, and (6) peril, that help in recognizing and understanding why particular conditions are more vulnerable to health-related stigma, what factors would worsen or reduce a given stigma, and why some stigmas may be easier to address than others.

(c) The Author(s). 2019 Open Access This article is distributed under the terms of the Creative Commons Attribution 4.0 International License (http://creativecommons.org/licenses/by/4.0/), which permits unrestricted use, distribution, and 
People often have co-morbidities and live with one or more of these health conditions and experience simultaneously different types of health-related stigma. Stigma is problematic because it affects people psychologically and restricts their social participation, and it can also create barriers to accessing healthcare, including retention in care for people living with HIV (PLHIV), relationships, education, and housing, thereby further marginalizing already vulnerable populations [2-4]. While the etiology of stigma may differ between conditions and, sometimes, cultural settings, the manifestations and psychosocial consequences of stigma and discrimination are remarkably similar $[3,5,6]$. Regardless of the condition, stigma is a dynamic process enacted through structures and individuals, mediated by relationships of power and control that are constantly being produced and reproduced [7]. Similarities across conditions are most likely due to the fact that the core of stigma is social in nature and therefore a common problem based on common human interpersonal responses to differentness and the mechanisms by which these responses might be expressed $[8,9]$. Nevertheless, responses to persons with the same condition may also differ in different locations, based on local differences in social determinants of stigma (e.g., religious beliefs). They may vary between conditions, depending on perceived cause and danger (e.g., in HIV or leprosy, people might avoid sharing a meal to avoid infection).

The cross-cutting nature of stigma is evidenced by the measurement methods used and the interventions that have been shown to be effective to reduce stigma or mitigate its impact across conditions [3, 10-13]. In many of the disciplines dealing with stigmatized conditions, the problem has been recognized and is addressed to some extent, but often only in a condition-specific manner. One challenge is that the funding, research, assessment tools, and interventions often address stigma related to only one particular condition. If measurement tools and interventions that assess and address common dimensions of stigma were possible, the scarce resources to address stigma could be used more efficiently and healthcare providers could use the same tools and approaches, across conditions. Several theoretical models describing common elements of stigma have been proposed, including those by Scambler [14, 15], Link and Phelan [16], Pescosolido et al. [17], and Weiss [5].

\section{Health-related stigma}

Stigma has been extensively studied in leprosy, mental health, HIV, epilepsy, and physical disability [3]. Lung cancer can also conjure a similar attribution of blame as that found with HIV and/or AIDS due to its frequent association with smoking cigarettes (tobacco) [18]. Yet, most of these have been studied only within their own field, often with development of condition-specific measurement instruments and interventions. From a health systems perspective, the application of generic tools for stigma assessment and of the same or similar interventions to address multiple stigmas would be highly beneficial. This benefit becomes even more evident in the light of an increasing frequency of co-morbidities and of the compounding impact of multiple intersecting stigmas.

To address this 'siloed approach' to stigma, the concept of 'health-related stigma' has been advocated $[19,20]$. It should be noted that discrimination, also known as enacted or experienced stigma, is part of the construct of stigma. Health-related stigma is a personal experience related to a health condition [21], characterized by the perception of exclusion, rejection, and blame [22], and contributes to psychological, physical, and social morbidity [23]. The judgment inherent in any health-related stigma is medically unwarranted and may adversely affect health status and health outcomes [22]. Health-related stigma is associated with depression and limited social support and acts as a barrier to healthcare access, treatment uptake, retention, and adherence [3, 24-31]. It thus contributes to increased severity of morbidity and disability [32,33], prolonged treatment duration and, through poor adherence, to development of drug resistance [34]. For example, stigma among individuals with mental illness can lead to adverse coping behaviors, including secrecy and withdrawal from others who do not share the stigmatizing status [35, 36], and has shown negative impact on treatment seeking (showing consistent small-to-moderate negative effects in a meta-synthesis [37]). In the field of HIV, stigma hinders access to and engagement in the HIV care continuum as a barrier to HIV testing, linkage to care, retention, and treatment adherence, and detrimentally impacts mental and physical wellbeing [30, 38, 39]. However, with the exception of several literature reviews on stigma measurement and interventions [3,10-12, 40], there is a gap in evidence in the published literature demonstrating the case for a cross-cutting approach to reduction and mitigation of the intrapersonal and interpersonal aspects of stigma. This paper seeks to address this gap using research data of studies on stigma and discrimination related to a number of diverse conditions.

\section{Conceptual model}

For this paper, we will use a conceptual model (see Fig. 1 ), which is both a simplification and an expansion of the model proposed by Weiss [5], which in turn was an extension of Scambler's Hidden Distress Model [14]. This model differentiates two main perspectives on health-related stigma, that of persons who are being stigmatized, and that of 'those who stigmatize'. We have called the latter 'sources of stigma' to allow inclusion of structural forms of stigma. It is important to realize that 


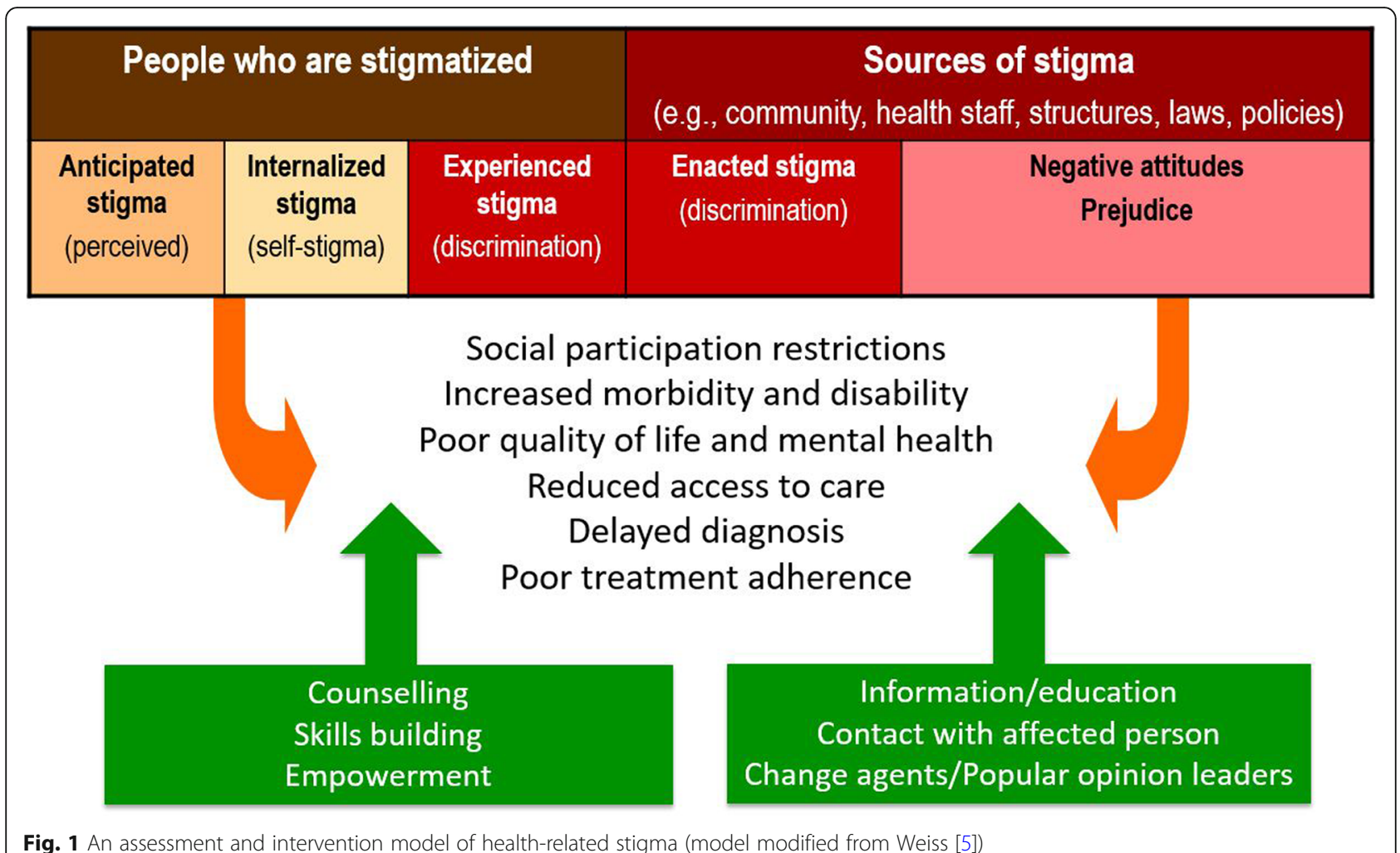

Fig. 1 An assessment and intervention model of health-related stigma (model modified from Weiss [5])

people may belong to both categories. For example, persons affected by one condition may stigmatize those with another. Also, health workers in leprosy, HIV, or mental health services may be stigmatized for working in such programs or for having the same condition; yet, they themselves may stigmatize the beneficiaries of the program. The model further distinguishes different types of stigma that can be recognized across conditions and cultures $[3,5,6,10]$. Both the two perspectives and the different types of stigma have a bearing on the assessment of stigma and on selecting relevant interventions. A comprehensive definition of health-related stigma encompassing differences in perspectives and types is offered by Weiss and Ramakrishna [22], "A social process or related personal experience characterized by exclusion, rejection, blame, or devaluation that results from experience or reasonable anticipation of an adverse social judgment about a person or group identified with a particular health problem".

We will demonstrate the cross-cutting nature of health-related stigma using data from studies of leprosy, HIV, TB, mental illness, inflammatory bowel disease, disability, obesity, and cancer. We will briefly present the instruments and interventions used, discuss the way they have been used across conditions, and then draw together the findings and lessons learnt regarding common aspects of stigma, proposing that 'generic health-related stigma' is a concept that can be used across stigmatized health conditions.

\section{Stigma measurement}

In an attempt to 'capture' stigma, as well as in assessing its severity and monitoring and evaluating the impact of interventions to reduce stigma, a large number of instruments have been developed, often within specific fields such as mental health [41] and HIV [28]. In addition, tools have been developed for many of the different domains of stigma such as perceived or anticipated stigma, internalized stigma, public stigma, stigma by association, and healthcare provider-based stigma [3, 9]. For an extensive review of the types of stigma assessments as well as their use in evaluating changes in mental health-related stigma interventions, please see the recent report from the U.S. National Academy of Sciences/Institute of Medicine [42]. Unfortunately, most instruments are both condition specific and limited to a particular domain of stigma (e.g., internalized or public stigma). Despite these silos of tools, a detailed analysis of stigma assessments showed that many similarities exist in the approaches used across conditions and in the issues addressed in the items used in questionnaires and scales [3]. It is informative to pay particular attention to the instruments that have been used across several conditions, including the Social Distance Scale (SDS) [41, 43], the 
Berger Stigma scale [24], the Internalized Stigma of Mental Illness (ISMI) scale [44], and the Explanatory Model Interview Catalogue (EMIC) [45]. Some of these have also been used across domains to assess internalized stigma, public stigma, and healthcare provider-based stigma. Having shown applicability across different conditions, we might consider the aspects of stigma contained in these instruments to be 'common' elements of stigma across illnesses.

\section{Instruments to measure public stigma \\ Social Distance Scale (SDS)}

The SDS was designed by Bogardus [46] to measure the level of acceptability of various types of social relationships between Americans and members of common ethnic groups [41, 47]. The first use of the SDS in the context of mental health was by Cumming and Cumming in 1957 [41]. The modified SDS has been widely used to measure mental health-related stigma and to understand the importance of labels attached to people with former mental illnesses [41, 48]. The modified version consists of seven questions that represent social contact with different degrees of distance, such as renting a room to someone with a condition under study, working in the same place, marrying one's child to a person with the condition(s), or engaging someone in child care. The SDS measures the acceptability of different degrees of social distance and thus, by inference, the attitude of the respondent to the person with the condition [43]. The SDS uses gender-specific, condition-adjusted vignettes that describe a man or a woman with typical features of the condition. Seven statements with a four-option 'degree of willingness' scale assess the willingness of the respondent to interact with the person described in the vignette ('Definitely willing' (0), 'Probably willing' (1), 'Probably not willing' (2), 'Definitely not willing' (3)). The SDS sum score represents the attitude of the respondent towards the condition.

\section{EMIC Community Stigma Scale (EMIC-CSS)}

The EMIC is available in different versions. The EMIC was designed by Weiss et al. [45] to examine the nature of the illness experience, including impact of stigma, on leprosy patients in India, with special reference to their mental health. The original EMIC combined quantitative questions that were scored and qualitative, open questions that provided explanations and more depth to the quantitative scores. The instrument was designed to be usable across conditions and has since been used in a variety of conditions. The more recent studies have often only used the quantitative EMIC stigma scale, rather than the 'mixed-methods instrument'. Later on, the instrument was adapted to assess the perception of stigmatizing attitudes and behavior among community members (lay persons), patients (affected persons) and healthcare workers [49]. The EMIC measures perceived attitude and behavior of the target group towards persons affected by the stigmatized condition. In various studies over the years, the length of the scale has varied from 8 to 25 items. The response scales contain four options, as follows: 'Yes' (2), 'Possibly' (1), 'No' (0), and 'Don't know' (0). In the 15 -item version, the sum score therefore ranges from 0 to 30 . In contrast to the SDS, the EMIC-CSS asks about the views and behavior of 'other people' in the community, rather than that of the respondent directly. This may help to minimize social desirability bias in responses.

\section{Instruments to measure stigma experienced by those with the condition \\ Berger Stigma Scale}

The Berger Stigma Scale was designed to measure stigma as perceived by PLHIV organized along four underlying factors, including personalized stigma (18 items); disclosure concerns (12 items); negative self-image (9 items); and concern with public attitudes about people with HIV (12 items) [24]. To develop the scale, Berger et al. [24] first developed a model of perceived stigma in PLHIV organized around precursors (perception of societal attitudes towards PLHIV and knowledge of personal sero-status), perceived stigma of having HIV (actual or potential experiences of social disqualification, limited opportunities, negative change in social identity), and possible responses to perceived stigma (change in self-image, emotional response to stigma, strategies to avoid or mitigate stigma, and redefined worldview and priorities). The actual scale items were selected and developed from a review of literature and expert consultation, field tested in the USA, and subjected to factor analysis. Responses to items are measures with a 4-point Likert scale ranging from 'strongly agree' to 'strongly disagree'. While quite lengthy, the scale has since been widely used and adapted both in a range of settings and for conditions other than HIV [50-53].

\section{EMIC affected persons}

The aim of the EMIC developed by Weiss et al. [45] was to "elicit illness-related perceptions, beliefs and practices in a cultural study of leprosy and mental health". The current 'EMIC affected persons' version is used to assess perceived and experienced stigma among those with the stigmatized condition. Its content is very similar to the EMIC-CSS.

\section{Internalized Stigma of Mental Illness (ISMI) scale}

The ISMI scale was developed to measure the subjective experience of stigma, especially the internalization of stigma [44]. ISMI subscales measure Alienation, Stereotype Endorsement, Perceived Discrimination, Social 
Withdrawal, and Stigma Resistance. The ISMI was developed together with people with mental illnesses. The instrument comprises 29 Likert items. Each statement is rated on a 4-point Likert scale ranging from 'strongly disagree' to 'strongly agree'. The ISMI was originally validated among mental health outpatients. Results showed that the ISMI had high internal consistency and test-retest reliability. Construct validity was supported by positive correlations with measures of stigma beliefs and depressive symptoms, and negative correlations with measures of self-esteem, empowerment, and recovery orientation. More recently, a brief version of the ISMI was developed and validated [54].

\section{Stigma interventions}

Information-based interventions are very likely the most common approach to addressing public stigma against any condition. However, they differ in content across conditions because they often address condition-specific knowledge gaps, stereotypes, fears, and other drivers of stigma; not infrequently, these are the only strategies used. However, while knowledge or education is often an essential part of stigma reduction, it is insufficient on its own [55-57].

Many authors have reviewed stigma reduction strategies and interventions from either a disease-specific or generic perspective [11, 57-63]. Evidence of effectiveness from well-designed studies using larger samples, particularly of longer-term impact, is scarce [58, 62]. However, available evidence suggests that stigma should be tackled at multiple levels, by using multiple strategies and the interventions must be context specific and continued or repeated to achieve a lasting impact $[6,8,11,64-66]$.

\section{Cross-condition methods to address public stigma Information-based interventions}

Information-based strategies are often used to reduce negative attitudes and perceived stigma in the community (public stigma). The assumption is that negative attitudes are likely to be based on a lack of knowledge, incorrect knowledge, myths, beliefs, and/or stereotypes about a given condition that can be 'corrected' with the right information [67]. Information-based interventions try to fill gaps in knowledge about the condition and dispel myths and demonstrate that stereotypes are often not true. An example is information about the availability of medical treatment for a given infectious disease; such information is assumed to contribute to reduction of stigma against that disease [68]. The second example is educating people with scientific facts, e.g., 'leprosy is an infectious disease' or 'leprosy is caused by a bacterium'. Health promotion media campaigns have been widely used, involving printed materials, such as posters in health facilities, and/or radio and television and internet messages [69]. It is crucial that education messages and campaigns take the local worldview, culture, language, and specific fears and beliefs into account $[65,66,70]$.

\section{Contact between persons with the condition and the community, health professionals, or others}

Facilitating contact between persons affected by a particular condition and members of the general public or healthcare workers has been shown to be effective in improving attitudes and in changing negative stereotypes [71]. This is based on the principle that attitudes can only be changed or replaced by positive attitudes when they have been shown to be dysfunctional [72]. Similarly, contact with individuals who 'moderately disconfirm' stereotypes is also important, i.e., with individuals who are symptomatic and are in treatment, but who also work, socialize, and have meaningful relationships [73]. The contact intervention has been used in different forms, either by facilitating direct, live contact or through electronic media. Examples are testimonies from persons affected in the community or from well-known 'champions', (participatory) videos and comics used during community events and meetings [74], screening on television, etc. Opportunities for discussion are also an important element.

\section{Change agents/Popular opinion leaders (POLs)}

Rooted in the Diffusion of Innovations Theory - a theory which focuses on how a new practice or idea can be dispersed through a social network to the point that it becomes a social norm [75] - a promising strategy to address stigmatization is the use of 'change agents' or POLs [76]. The hypothesis is that, when such POLs display positive attitudes, spread a non-stigmatizing message, or even fight enacted stigma in a social group, they model a new behavior and thus alter the perception and eventually even the social norm. POL interventions have been profusely and successfully applied, across different (stigmatizing) populations and across different continents, in HIV and sexually transmitted infection interventions [77-79], and more recently also in the context of the TB/HIV co-epidemic [80]. The latter on-going trial is the first attempt to apply the POL strategy to implement a cross-cutting, and thus not disease specific, stigma-reduction intervention (Rau et al., submitted for publication). Crucial to the success of such POL interventions is the selection and training of these POLs. When community members identify themselves as the members who are influential in a stratified manner, for example, by asking randomly selected respondents to nominate influential community members or by asking gatekeepers (village or organization heads) to recommend popular individuals [78], and when these potential 
POLs are then adequately trained, increasing knowledge as well as adapting behavior, this approach has the potential to be a suitable cross-cutting strategy applicable to a wide range of stigmatized conditions [76].

\section{Cross-condition methods to address stigma experienced by persons affected \\ (Peer) counselling}

Peer counselling is an intervention in which suitable persons with the same condition are selected and offered training in counselling [81]; this focuses on listening and problem-solving skills, as well as increasing knowledge about the condition and, as in the case of a study in Indonesia [82], about human rights. In the case of peer counsellors, the counsellor can also serve as a role model to the counselee. Peer counselling and similar approaches have also been used in the fields of mental health and HIV, although terms like 'peer educator,' 'expert client', or 'community-linkage facilitator' are more commonly used. However, these do not necessarily engage HIV-positive peers as educators, but rather a variety of other peers such as students in schools (e.g., Denison et al. [83]). Counselling, as part of 'voluntary counselling and testing' has been extensively used in HIV, but not primarily as a stigma-reduction strategy.

\section{Skills building and empowerment}

Interventions for socioeconomic development or improvement of the livelihoods of persons affected can be seen as economic empowerment [84, 85]. By enabling persons who are stigmatized to find a job or improve their income, self-esteem and the feeling of self-worth are improved [86]. Importantly, people get hope that there is a way out of their predicament. In low- and middle-income countries, such socioeconomic interventions are often linked to people organizing themselves in self-help groups (SHGs) [87], which may then start a saving scheme and/or be linked to a micro-finance institution (Dadun et al., submitted). Collateral-free individual or group micro-credit loans are then given from the collective savings or by the bank or institution [88]. People may start a small business or invest the loan in agricultural activities. Being able to contribute to the family income or to the community in this way often helps greatly in regaining identity and respect, either reducing public stigma or offering additional resilience to cope with it [72, 89].

\section{Evidence of how measurement instruments are used across conditions}

Table 1 shows examples of stigma instruments that have been used across several conditions to measure attitudes and perceived and enacted stigma among the public or community. The SDS has a long history and was originally designed to assess willingness to associate with persons of different ethnic backgrounds [46]. Link et al. [90] used a version adapted for mental health to assess attitudes towards persons with mental health conditions. Lee et al. [91] assessed 'victim blaming' of persons with HIV or AIDS among US college students using the SDS. Peters et al. [43] used social distance as a proxy for respondent attitudes towards persons affected by leprosy in Indonesia, and a study in Germany assessed stigma against persons with obesity using the SDS [92]. The EMIC-CSS has been used across conditions most often, including in a study assessing attitudes and perceived behavior against persons with onchocerciasis [93], mental health conditions [49], Buruli ulcer [94], tuberculosis [95], and leprosy [43, 96, 97]. Additionally, the cultures were very diverse, including four countries in Africa and four in Asia.

In the same way, instruments used to assess stigma experienced by persons affected across a range of conditions are shown in Table 2. The Berger Stigma Scale, originally designed to measure perceived and experienced stigma among PLHIV [24], was successfully adapted for use in leprosy [98] and meticillin-resistant Staphylococcus aureus [53]. The ISMI was used most frequently, with no less than 81 papers covering $42 \mathrm{com}$ pleted translations [13]. Most studies used the instrument in mental health, but other studies demonstrated the usefulness of the ISMI among persons with substance abuse, leprosy, HIV, and inflammatory bowel disease [96, 99-101]. The EMIC Affected Persons scale has been used most widely in terms of range of conditions. Originally designed to measure the impact of leprosy on the mental health of persons affected [45], it has since been used to measure experienced stigma related to mental health conditions, including depression, schizophrenia and bi-polar disorder [102-104], onchocerciasis [105], Buruli ulcer [94], HIV [101], TB [106], and leprosy [96].

\section{Evidence of how stigma interventions are used across conditions}

Interventions to reduce public stigma were also very similar across diverse conditions.

Table 3 shows examples of information-based interventions being used to address attitudes of college students towards persons with mental health conditions in the USA [107], general public attitudes towards HIV in Ghana [108], and community attitudes to leprosy in Indonesia [109]. Another very commonly used stigma intervention is the contact intervention, which was used with success to improve attitudes to mental illness among college students in the USA [110], attitudes towards PLHIV among nurses in Hong Kong [111], and 
Table 1 Instruments used to measure public stigma

\begin{tabular}{|c|c|c|c|c|c|c|}
\hline Author & Country & Condition & Target group & $N$ & Evidence of validity & Comments \\
\hline \multicolumn{7}{|l|}{ SDS } \\
\hline Link et al. [90] & USA & $\begin{array}{l}\text { Mental health } \\
\text { conditions }\end{array}$ & $\begin{array}{l}\text { Random sample of } \\
\text { Ohio residents }\end{array}$ & 151 & Alpha 0.92 & \\
\hline Lee et al. [91] & USA & HIV and AIDS & $\begin{array}{l}\text { College } \\
\text { students }\end{array}$ & 818 & $\begin{array}{l}\text { No validation } \\
\text { was reported }\end{array}$ & $\begin{array}{l}\text { The SDS in this study used different } \\
\text { items from the one adapted by } \\
\text { Link et al. [90] used in all other studies }\end{array}$ \\
\hline $\begin{array}{l}\text { Peters et al. [43, } \\
\text { 109] }\end{array}$ & Indonesia & Leprosy & $\begin{array}{l}\text { Community } \\
\text { in an endemic } \\
\text { district }\end{array}$ & $\begin{array}{l}259,213 \\
\text { and } 375\end{array}$ & $\begin{array}{l}\text { Alpha } 0.87, \text { SDC }^{a} 0.60 \text {, } \\
\text { ICC } 0.75(95 \% \text { Cl } 0.62-0.84) \text {; } \\
\text { no floor or } \\
\text { ceiling effects }\end{array}$ & \\
\hline $\begin{array}{l}\text { Sikorski } \\
\text { et al. [92] }\end{array}$ & Germany & Obesity & $\begin{array}{l}\text { Telephone sample } \\
\text { of general public }\end{array}$ & 1008 & Alpha 0.86 & \\
\hline $\begin{array}{l}\text { Pachankis } \\
\text { et al. [120] }\end{array}$ & USA & $\begin{array}{l}44 \text { health } \\
\text { conditions }\end{array}$ & $\begin{array}{l}\text { Experts and } \\
\text { general public }\end{array}$ & 1025 & $\begin{array}{l}\text { Alpha } 0.84 \text { (expert raters); } \\
0.83 \text { general public raters }\end{array}$ & \\
\hline \multicolumn{7}{|l|}{ EMIC } \\
\hline $\begin{array}{l}\text { Vlassoff } \\
\text { et al. [93] }\end{array}$ & $\begin{array}{l}\text { Nigeria } \\
\text { Cameroon, } \\
\text { Ghana, Uganda }\end{array}$ & Onchocerciasis & $\begin{array}{l}\text { Unaffected } \\
\text { persons }\end{array}$ & 410 & Alpha 0.76 & 12-item EMIC was used \\
\hline $\begin{array}{l}\text { Chowdhury } \\
\text { et al. [49] }\end{array}$ & India & $\begin{array}{l}\text { Mental health } \\
\text { conditions }\end{array}$ & $\begin{array}{l}\text { Non-affected } \\
\text { lay persons }\end{array}$ & 21 & Kappa 0.90 (inter-rater) & $20-25$ items, depending on version \\
\hline $\begin{array}{l}\text { Stienstra } \\
\text { et al. [94] }\end{array}$ & Ghana & Buruli ulcer & Healthy controls & 33 & Alpha 0.76 & 15-item EMIC \\
\hline $\begin{array}{l}\text { Rensen } \\
\text { et al. [96] }\end{array}$ & India & Leprosy & $\begin{array}{l}\text { Non-affected } \\
\text { community }\end{array}$ & 806 & $\begin{array}{l}\text { Alpha } 0.83 \text {; no floor } \\
\text { or ceiling effects }\end{array}$ & 13-item EMIC \\
\hline $\begin{array}{l}\text { Peters et al. } \\
{[43,109]}\end{array}$ & Indonesia & Leprosy & $\begin{array}{l}\text { Community in an } \\
\text { endemic district }\end{array}$ & $\begin{array}{l}259,213 \\
\text { and } 375\end{array}$ & $\begin{array}{l}\text { Alpha } 0.83, S D C^{a} 0.81 \\
\text { ICC } 0.84(95 \% \text { CI } 0.75-0.90) \text {; } \\
\text { no floor or ceiling effects }\end{array}$ & 15-item EMIC \\
\hline $\begin{array}{l}\text { Kaehler } \\
\text { et al. [97] }\end{array}$ & Thailand & Leprosy & $\begin{array}{l}\text { Community in an } \\
\text { endemic district }\end{array}$ & 257 & No validation was reported & 15-item EMIC \\
\hline $\begin{array}{l}\text { Adhikari } \\
\text { et al. [133] }\end{array}$ & Nepal & Leprosy & $\begin{array}{l}\text { Community in an } \\
\text { endemic district }\end{array}$ & 281 & No validation was reported & 15-item EMIC \\
\hline $\begin{array}{l}\text { Sermrittirong } \\
\text { et al. [95] }\end{array}$ & Thailand & $\begin{array}{l}\text { Leprosy, } \\
\text { tuberculosis }\end{array}$ & $\begin{array}{l}\text { Community in an } \\
\text { endemic district }\end{array}$ & 236 & No validation was reported & 15-item EMIC \\
\hline
\end{tabular}

${ }^{\mathrm{a}} \mathrm{SDC}$ group Smallest detectable change in the group (based on standard error of measurement (SEM), using the formula $1.96 \times \sqrt{ } 2 \times \mathrm{SEM}$ divided $\sqrt{ } \mathrm{n}$ ) EMIC Explanatory Model Interview Catalogue, ICC intraclass correlation coefficient, SDC smallest detectable change, SDS Social Distance Scale

attitudes of community members towards persons affected by leprosy in Indonesia [74, 109]. Education about the condition and related beliefs and fears, and contact between persons with the concerned conditions and members of the community or other target group are often used together; this combination of interventions has been shown to work across conditions and cultures [11, 60, 62, 109, 111, 112]. Training and engagement of POLs or change agents was successful in different conditions (leprosy, HIV, and TB) and very different cultural settings (Nepal, USA, Peru, China, and South Africa) $[77,78,113,114]$.

Interventions to mitigate the impact of stigma have addressed the mental wellbeing of the persons affected, their resilience, self-efficacy and sense of self-worth, and ability to speak up for themselves through empowerment, skills building, and participation in the actual interventions. Nuwaha et al. [115] and Jürgensen et al.
[116] found home-based counselling to be successful in reducing different aspects of HIV-related stigma in Uganda and Zambia. Conner et al. [117] found peer education was effective to reduce internalized stigma in a small study with older adults with mental health conditions in the USA. Across the globe, Lusli et al. [82] trained lay and peer counsellors among persons affected by leprosy in Cirebon, Indonesia; they, in turn, counselled others. Their approach, which included building resilience, restoring dignity, and awareness of human rights, was shown to be effective in reducing stigma, improving social participation, and improving quality of life among the counselees [118].

Skills building and empowerment of persons who are stigmatized is another strategy shown to be effective across conditions and cultures. The Stigma Elimination Project in south Nepal trained a small group of persons with visible signs of leprosy who showed leadership 
Table 2 Instruments used to measure anticipated/perceived, internalized or experienced stigma

\begin{tabular}{|c|c|c|c|c|c|c|}
\hline Author & Country & Condition & Target group & $N$ & Evidence of validity & Comments \\
\hline \multicolumn{7}{|c|}{ Berger stigma scale } \\
\hline $\begin{array}{l}\text { Berger } \\
\text { et al. [24] }\end{array}$ & USA & HIV & $\begin{array}{l}\text { People } \\
\text { with HIV }\end{array}$ & 318 & $\begin{array}{l}\text { Alpha } 0.96 \text {; alpha sub-scales } 0.90-0.93 \text {, } \\
\text { correlation coefficient reliability } 0.92 \text {. } \\
\text { Construct validity supported by correlation } \\
\text { with Rosenberg Self-esteem scale and Center } \\
\text { for Epidemiological Studies-Depression scale }\end{array}$ & \\
\hline $\begin{array}{l}\text { Dadun } \\
\text { et al. [98] }\end{array}$ & Indonesia & Leprosy & $\begin{array}{l}\text { Persons } \\
\text { affected } \\
\text { by leprosy }\end{array}$ & 392 & $\begin{array}{l}\text { Alpha } 0.88 \text {; sub-scale alphas } 0.79-0.84 \text {, } \\
\left.\text { SDC }^{\mathrm{a}} 1.37 \text {, ICC } 0.75 \text { ( } 95 \% \mathrm{Cl} 0.64-0.83\right) \text {; } \\
\text { no floor or ceiling effects; construct validity } \\
\text { supported by correlation with the P-scale } \\
\text { and WHOQOL-BREF }\end{array}$ & $\begin{array}{l}\text { Renamed 'SARI Stigma } \\
\text { Scale' because of } \\
\text { substantial changes } \\
\text { to structure }\end{array}$ \\
\hline $\begin{array}{l}\text { Rump } \\
\text { et al. [53] }\end{array}$ & Netherlands & MRSA & MRSA carriers & 57 & $\begin{array}{l}\text { Validity was supported by correlation } \\
\text { with the RAND mental health inquiry }\end{array}$ & $\begin{array}{l}\text { An adapted version } \\
\text { was used }\end{array}$ \\
\hline \multicolumn{7}{|l|}{ ISMI } \\
\hline $\begin{array}{l}\text { Boyd Ritsher } \\
\text { et al. [44] }\end{array}$ & USA & $\begin{array}{l}\text { Mental health } \\
\text { conditions }\end{array}$ & $\begin{array}{l}\text { Mental health } \\
\text { outpatients }\end{array}$ & 127 & $\begin{array}{l}\text { Alpha } 0.90 \text { (sub-scales } 0.58-0.80) ; \\
\text { test-retest reliability } r=0.92(n=16) \\
\text { (sub-scales } 0.68-0.94) ; \text { good } \\
\text { construct validity }\end{array}$ & 29 items \\
\hline $\begin{array}{l}\text { Brohan } \\
\text { et al. [134] }\end{array}$ & $\begin{array}{l}13 \text { European } \\
\text { countries }\end{array}$ & $\begin{array}{l}\text { Bipolar disorder } \\
\text { and depression }\end{array}$ & $\begin{array}{l}\text { Mental } \\
\text { health patients }\end{array}$ & 1182 & $\begin{array}{l}\text { Alpha } 0.94 \text {; construct validity supported } \\
\text { by strong correlations with an } \\
\text { empowerment scale and a devaluation } \\
\text { and discrimination scale }\end{array}$ & $\begin{array}{l}\text { 24-item ISMI was } \\
\text { used, excluding the } \\
\text { Resilience sub-scale }\end{array}$ \\
\hline $\begin{array}{l}\text { Singh } \\
\text { et al. [135] }\end{array}$ & India & Mental health & $\begin{array}{l}\text { Persons with } \\
\text { severe mental } \\
\text { disorders }\end{array}$ & 161 & $\begin{array}{l}\text { Alpha } 0.86 \text {; ICC test-retest reliability } \\
(n=31) \text { sub-scales range } 0.84-0.96 ; \\
5 \text {-component structure supported } \\
\text { by factor analysis; good correlation } \\
\text { with EMIC }\end{array}$ & \\
\hline $\begin{array}{l}\text { Luoma } \\
\text { et al. [99] }\end{array}$ & USA & $\begin{array}{l}\text { Substance } \\
\text { abuse }\end{array}$ & $\begin{array}{l}\text { Adults with a } \\
\text { substance use } \\
\text { disorder }\end{array}$ & 88 & $\begin{array}{l}\text { Alpha } 0.82 \text { and } 0.92 \text { at pre- and } \\
\text { post-assessment }\end{array}$ & \\
\hline $\begin{array}{l}\text { Stevelink } \\
\text { et al. [101] }\end{array}$ & India & $\begin{array}{l}\text { HIV } \\
\text { Leprosy }\end{array}$ & $\begin{array}{l}\text { Patients/persons } \\
\text { affected }\end{array}$ & $\begin{array}{l}95 \text { HIV } \\
95 \text { leprosy }\end{array}$ & $\begin{array}{l}\text { Alpha } 0.87 \\
\text { Alpha } 0.91\end{array}$ & \\
\hline $\begin{array}{l}\text { Rensen } \\
\text { et al. [96] }\end{array}$ & India & Leprosy & $\begin{array}{l}\text { Affected } \\
\text { persons }\end{array}$ & 806 & $\begin{array}{l}\text { Alpha } 0.96 \text {; sub-scale alphas } 0.79-0.96 \text {; } \\
\text { weighted kappa } 0.62(n=49) \\
\text { no floor or ceiling effects }\end{array}$ & 18-item ISMI \\
\hline $\begin{array}{l}\text { Taft et al. } \\
{[100]}\end{array}$ & USA & $\begin{array}{l}\text { Inflammatory } \\
\text { bowel disease }\end{array}$ & $\begin{array}{l}\text { Irritable bowel } \\
\text { disease patients }\end{array}$ & 191 & No validation was reported & \\
\hline $\begin{array}{l}\text { Arachchi } \\
\text { et al. [136] }\end{array}$ & Sri Lanka & Leprosy & $\begin{array}{l}\text { Affected } \\
\text { persons }\end{array}$ & 132 & No validation was reported & \\
\hline \multicolumn{7}{|c|}{ EMIC affected persons } \\
\hline $\begin{array}{l}\text { Weiss } \\
\text { et al. [45] }\end{array}$ & India & $\begin{array}{l}\text { Leprosy, } \\
\text { mental health }\end{array}$ & Patients & $\begin{array}{l}56+31 \\
\text { controls }\end{array}$ & $\begin{array}{l}\text { Item-wise kappa values 0.62-0.93 } \\
(n=16-18) ; \text { association with } \\
\text { established mental health } \\
\text { instruments (SCID and HDARS) } \\
\text { supported construct validity }\end{array}$ & 8-item EMIC \\
\hline $\begin{array}{l}\text { Raguram } \\
\text { et al. } \\
{[102,103]}\end{array}$ & India & $\begin{array}{l}\text { Depression, } \\
\text { schizophrenia }\end{array}$ & $\begin{array}{l}\text { Patients } \\
\text { Family, } \\
\text { caretakers }\end{array}$ & $\begin{array}{l}80 \\
80\end{array}$ & $\begin{array}{l}\text { Alpha } 0.71 \\
\text { Alpha } 0.81\end{array}$ & $\begin{array}{l}\text { 10-item EMIC } \\
\text { 13-item EMIC }\end{array}$ \\
\hline $\begin{array}{l}\text { Brieger } \\
\text { et al. [105] }\end{array}$ & Nigeria & Onchocerciasis & Patients & 500 & No validation was reported & $\begin{array}{l}\text { 13-item EMIC } \\
\text { was used }\end{array}$ \\
\hline $\begin{array}{l}\text { Vlassoff } \\
\text { et al. [93] }\end{array}$ & $\begin{array}{l}\text { Nigeria } \\
\text { Cameroon } \\
\text { Ghana } \\
\text { Uganda }\end{array}$ & Onchocerciasis & Patients & 469 & Alpha 0.80 & $\begin{array}{l}\text { 13-item EMIC } \\
\text { was used }\end{array}$ \\
\hline $\begin{array}{l}\text { Chowdhury } \\
\text { et al. [49] }\end{array}$ & India & $\begin{array}{l}\text { Mental health } \\
\text { conditions }\end{array}$ & Patients & 25 & Kappa 0.89 (inter-rater) & $\begin{array}{l}20-25 \text { items, depending } \\
\text { on version }\end{array}$ \\
\hline
\end{tabular}


Table 2 Instruments used to measure anticipated/perceived, internalized or experienced stigma (Continued)

\begin{tabular}{|c|c|c|c|c|c|c|}
\hline Author & Country & Condition & Target group & $N$ & Evidence of validity & Comments \\
\hline $\begin{array}{l}\text { Stienstra } \\
\text { et al. [94] }\end{array}$ & Ghana & Buruli ulcer & Patients & 33 & $\begin{array}{l}\text { Alpha } 0.65 \\
\text { (of } 11 \text { items asked of } \\
\text { both patients and controls) }\end{array}$ & 15-item EMIC \\
\hline $\begin{array}{l}\text { Weiss et al. } \\
{[106]}\end{array}$ & $\begin{array}{l}\text { Bangladesh } \\
\text { India Malawi } \\
\text { Colombia }\end{array}$ & Tuberculosis & Patients & $\begin{array}{l}102 \\
127 \\
100 \\
98\end{array}$ & $\begin{array}{l}\text { Alpha } 0.77 \\
\text { Alpha } 0.85 \\
\text { Alpha } 0.63 \\
\text { Alpha } 0.65\end{array}$ & 18-item EMIC \\
\hline $\begin{array}{l}\text { Stevelink } \\
\text { et al. [101] }\end{array}$ & India & $\begin{array}{l}\text { HIV } \\
\text { Leprosy }\end{array}$ & $\begin{array}{l}\text { Patients/persons } \\
\text { affected }\end{array}$ & $\begin{array}{l}95 \text { HIV } \\
95 \text { leprosy }\end{array}$ & $\begin{array}{l}\text { Alpha } 0.76 \\
\text { Alpha } 0.83\end{array}$ & \\
\hline $\begin{array}{l}\text { Rensen } \\
\text { et al. [96] }\end{array}$ & India & Leprosy & Patients & 806 & $\begin{array}{l}\text { Alpha } 0.88 \text {; weighted kappa } 0.70 \text {; } \\
\text { no floor or ceiling effects }\end{array}$ & 17-item EMIC \\
\hline $\begin{array}{l}\text { Grover } \\
\text { et al. [104] }\end{array}$ & India & Bi-polar disorder & Patients & 185 & $\begin{array}{l}\text { Alpha } 0.94 \text {; good correlation } \\
\text { with ISMI and Participation } \\
\text { scale scores }\end{array}$ & 15-item EMIC \\
\hline $\begin{array}{l}\text { Arachchi } \\
\text { et al. [136] }\end{array}$ & Sri Lanka & Leprosy & Patients & 132 & No validation was reported & Not reported \\
\hline
\end{tabular}

${ }^{\mathrm{a}} \mathrm{SDC}$ group $\mathrm{Smallest}$ detectable change in the group (based on standard error of measurement (SEM), using the formula $1.96 \times \sqrt{ } 2 \times \mathrm{SEM}$ divided $\sqrt{ } \mathrm{n}$ ) ICC intraclass correlation coefficient, ISMI Internalized Stigma of Mental IIIness, MRSA Meticillin-resistant Staphylococcus aureus, P-scale Participation Scale, WHOQOL-BREF WHO Quality of Life scale - Brief

${ }^{\mathrm{b}}$ SCID Structured Clinical Interview for DSM-III-R; HDARS Hamilton Depression and Anxiety Rating Scale,

potential [76], who became leaders of a rapidly growing number of SHGs. After 3 years, the level of social participation of SHG members was at the level or better than that of a community control group. Bellamy and Mowbray [119] found a 'supported education program' to be successful in empowering adults with mental health conditions in the USA and strengthening their self-efficacy to (re-)enter post-secondary education. Dalal [72] reported empowerment of persons with disabilities in north India to be very successful in overcoming shame, increasing social participation, and improving health outcomes as well as in changing community attitudes towards disability. Uys et al. [71] used skills building and empowerment among both nurses and PLHIV to reduce stigma and improve quality of care in healthcare settings in five African countries. This was successful in reducing stigma and increasing self-esteem among PLHIV, but did not affect stigma among the nurses. However, the HIV testing behavior of the latter improved significantly.

\section{The concept of health-related stigma}

The current paper demonstrates that 'health-related stigma' is a viable concept with clearly identifiable characteristics that are similar across a variety of stigmatized health conditions in very diverse cultures. The etiology of stigma differs between conditions and sometimes between cultural settings. For example, persons with schizophrenia are stigmatized because people perceive them to be unpredictable or dangerous, while PLHIV may be stigmatized and discriminated against because, in certain cultures, HIV is associated with homosexuality and promiscuity, and because it is perceived to be a highly infectious, as well as fatal and incurable disease. Leprosy is often stigmatized because of the notion that the person affected has committed a sin or broken a taboo, either in this or a previous life; it may also be due to fear of the associated disfigurements. Even regarding the etiology and origins of stigma and discrimination, 'shared dimensional features' can be readily recognized. Pachankis et al. [120] used the six features identified by Jones et al. [1] (aesthetics, concealability, course, disruptiveness, origin, and peril) as a taxonomy for characterizing and investigating the perceived burden of stigma on health and wellbeing across no less than 93 health and other conditions.

As noted in the Background section, the expressions or manifestations and psychosocial consequences of stigma and discrimination are often remarkably similar, even across very different cultures and levels of socioeconomic development [3, 5, 6, 8]. Stigma starts when salient differences between people are recognized, labelled, and connected to stereotypes or social identities [16]. This process leads on to a separation between 'us' and 'them', resulting in status loss and discrimination. Depending on the culture and time, these differences may include a large variety of characteristics, including ethnicity, sexual orientation, skin color, body weight, religious beliefs, and a wide range of health conditions. In this paper, we limited ourselves to health conditions, though we are well aware of the intersectionality of stigma where health-related and other stigmas interacted and may compound each other [121-123]. A substantial body of literature addresses the intersectionality of stigma related to particular conditions. For example, Lowie et al. [121] examined how gender, race, sexual 
Table 3 Interventions used across conditions to address public stigma (attitudes and behavior)

\begin{tabular}{|c|c|c|c|c|c|}
\hline Author & Country & Condition & Target group & $N$ & Evidence of effectiveness \\
\hline \multicolumn{6}{|c|}{ Information-based approaches } \\
\hline $\begin{array}{l}\text { Masuda } \\
\text { et al. } \\
\text { [107] }\end{array}$ & USA & $\begin{array}{l}\text { Psychological } \\
\text { disorders }\end{array}$ & $\begin{array}{l}\text { College } \\
\text { students }\end{array}$ & $\begin{array}{l}95 \\
(43+52)\end{array}$ & $\begin{array}{l}\text { The CAMI scores for the educational } \\
\text { workshop lowered at post-intervention } \\
\text { and 1-month follow-up among } \\
\text { participants with higher levels of } \\
\text { psychological flexibility (scored } 67 \\
\text { or higher on the Acceptance } \\
\text { and Action Questionnaire) }\end{array}$ \\
\hline $\begin{array}{l}\text { Boulay } \\
\text { et al. } \\
{[108]}\end{array}$ & Ghana & HIV & $\begin{array}{l}\text { General } \\
\text { public }\end{array}$ & 2746,2926 & $\begin{array}{l}\text { Attitudes related to a punitive } \\
\text { response to PLHA both improved over } \\
\text { time and were positively associated } \\
\text { with exposure to the program's } \\
\text { campaign; overall, respondents } \\
\text { exposed to the campaign were } 45 \% \\
\text { more likely than those not exposed to } \\
\text { be willing to care for a HIV-infected } \\
\text { relative, and } 43 \% \text { more likely to believe } \\
\text { that an HIV-infected female teacher } \\
\text { should be allowed to continue } \\
\text { teaching }\end{array}$ \\
\hline $\begin{array}{l}\text { Peters } \\
\text { et al. [109] }\end{array}$ & Indonesia & Leprosy & $\begin{array}{l}\text { Community in } \\
\text { an endemic } \\
\text { district }\end{array}$ & $\begin{array}{l}213 \text { and } \\
375\end{array}$ & $\begin{array}{l}\text { Knowledge about leprosy increased } \\
\text { and that negative attitudes reduced } \\
\text { significantly; at baseline, } 87 \% \\
\text { considered leprosy curable and } 31 \% \\
\text { thought leprosy was still contagious } \\
\text { after treatment; this had improved } \\
\text { after the contact event to } 98 \% \text { and } \\
7 \% \text {, respectively }\end{array}$ \\
\hline
\end{tabular}

Comments

Contact

Peters Indonesia Leprosy Community in an 213

et al. [109]

endemic district and 375

$\begin{array}{lll}\begin{array}{l}\text { Corrigan } \\ \text { et al. [110] }\end{array} & \text { USA } & \begin{array}{l}\text { Mental } \\ \text { illness }\end{array}\end{array}$

Paxton

[137]

$?$

HIV

Young people

1230

\begin{tabular}{|c|c|c|c|c|}
\hline $\begin{array}{l}\text { Jys et al. } \\
71]\end{array}$ & $\begin{array}{l}\text { Lesotho, Malawi } \\
\text { South Africa, }\end{array}$ & HIV & $\begin{array}{l}\text { Nurses } \\
\text { PLHA }\end{array}$ & $\begin{array}{l}41 \text { PLHA } \\
134 \text { nurses }\end{array}$ \\
\hline
\end{tabular}

The EMIC and SDS stigma scores reduced both among those attending 'contact events' (effect sizes 0.75 and 0.81 , respectively) and in the wider community (effect size 0.47 and 0.54 )

Participants in the contact intervention group showed significant reduction in avoidance and segregation factors with the Attribution Questionnaire at post-intervention and 1-week followup; participants in contact condition also showed significant reduction in pity and improvement in power from pre- to post-intervention

HIV-positive speakers were effective in decreasing fear and stigmatization among the audience; meeting HIVpositive people decreased fear and prejudice, reinforced messages about protective behavior and increased the belief that HIV is preventable; the im proved attitudes remained significant over 3 months

PLHA involved in the intervention teams reported less stigma and increased self-esteem; nurses in the intervention teams and those in the target group reported no reduction in stigma or increases in self-esteem and self-efficacy, but their HIV testing be havior increased significantly
CAMl administered at beginning and end of workshop, and at 1-month follow-up

Post-intervention result measured after 3 months

Contact was through testimonies on video plus a live testimony given at 'contact events' with community groups: post-intervention results were measured on average

$1-1.5$ years after the contact events

Contact through video was used; measures administered pre-test, post-test, 1-week follow-up

A pre- and post-test was done to measure stigma, self-esteem and self-efficacy; the post-test was conducted within 1 month after the intervention 
Table 3 Interventions used across conditions to address public stigma (attitudes and behavior) (Continued)

\begin{tabular}{lllll}
\hline Author & Country & Condition & Target group & N \\
\hline Yiu et al. & Hong Kong & HIV & Nursing students & 89 \\
[111] & & & &
\end{tabular}

Evidence of effectiveness
In both the knowledge-only group and
the knowledge-contact group,
significant improvement in AIDS
knowledge, stigmatizing attitudes, fear
of contagion, willingness to treat, and
negative affect were found at post-test;
the effects on AIDS knowledge, fear of
contagion, willingness to treat, and
negative affect were sustained at
follow-up for both groups
Intergroup comparisons at post-test
showed that the effectiveness of the
knowledge-contact program was
significantly greater than the
knowledge program in improving
stigmatizing attitudes; no significant
difference between the two groups
was found at follow-up

Change agents/ Popular opinion leaders

$\begin{array}{lll}\text { Kelly } & \text { USA } & \text { HIV } \\ \text { et al. [114] }\end{array}$

Cross \& Nepa

Choudhury

[76]

$\begin{array}{ll}\text { Leprosy } \quad \text { Community } & 152 \mathrm{SHG} \\ & \text { participants }\end{array}$

HIV

et al. [77]

Li et al. [78] China
HIV
Community

workers participants

1327 POL, 1722 comparison 
epilepsy, HIV, leprosy, TB, Buruli ulcer, onchocerciasis, and physical disability in his review of measurement of health-related stigma, noting many commonalities in the approaches and tools used to measure different stigmas. A more recent review investigated stigma across 10 neglected tropical diseases and noted many similarities in the types of stigma reported, the manifestations, and the approaches used to mitigate stigma [10]. Although not limited to health-related stigma, the study of Pachankis et al. [120] included 44 health conditions. They examined similarities and differences regarding each of the six characteristics proposed by Jones et al. [1] and investigated their association with a range of different stigma-related measures, including the SDS. One of the findings was that "Visibility and course were not associated with social distance. In contrast, participants indicated a desire for greater social distance with respect to stigmatized statuses that were perceived as disruptive, aesthetically unappealing, onset controllable, and perilous" [120]; these features are shared by many stigmatized health conditions.

The above findings show that there is a scientific rationale for the concept of health-related stigma, as proposed by Weiss et al. [19] and Scambler [20, 128]. A more generic approach to the study of health-related stigma opens up important practical opportunities. This paper illustrated this with two aspects of work - stigma measurement and interventions to reduce or mitigate stigma.

\section{Towards common stigma measurement approaches for health-related stigma}

If it were possible to measure stigma and discrimination using generic instruments, this would have clear advantages, especially for use in public health programs and social services. Use of measurement tools requires training. With a different tool for each condition, staff in health and social services have to learn and keep up with many different instruments, some of which they may only use infrequently, thus never acquiring a 'feel' for the instrument and the results it produces. In the current age of mobile data collection, one could envisage that adaptation of a given instrument to a particular condition would be done by just indicating on the opening screen which condition one wants to test; the software would automatically adapt the instrument to that condition. Tools for which this would be very easy are those indicated in Table 1 and Table 2. Instruments like the SDS, EMIC, and ISMI were shown to be highly suitable for use across conditions since the content includes manifestations and impact common to many stigmatized health conditions.

Researchers in the health-related stigma field can clearly also benefit from the use of instruments that can be adapted very easily for use across conditions; the study of Pachankis et al. [120] illustrates this point very nicely.

A disadvantage of using generic instruments is a potential lack of sensitivity and/or specificity. Where this would be required, one could envisage using an add-on module comprising a few condition-specific items. This would retain the advantage of a common core of items that can be used and compared across conditions. A very similar approach that is widely accepted is the measurement of health-related quality of life. Generic tools like the WHO Quality of Life scale, abbreviated version (WHOQOL-BREF), and the Short Form 36 items are used across a myriad of disabling and stigmatized conditions and in very culturally diverse circumstances. In certain situations, add-on modules are used, such as the WHOQOL-DIS for disability, or the WHOQOL-SRPB for the effects of spirituality, religion and personal beliefs.

\section{Towards common stigma intervention approaches for health-related stigma}

Many of the same advantages that apply to cross-condition measurement tools also apply to interventions.

Table 3 and Table 4 illustrate the several interventions that have already been used successfully with multiple conditions; this is hardly surprising because of the common social and psychological processes underlying health-related stigma $[5,16,19]$. Manifestations, such as difficulties in finding and maintaining employment, broken relationships, and impacts on socioeconomic status and mental wellbeing, including shame and reduced self-esteem, are common across conditions, thus offering entry points for cross-cutting interventions. It should be noted that, although the studies included have been classified under one, or at the most two, intervention types, almost all studies used multiple interventions. Sometimes, these addressed different levels and sometimes they addressed both the sources of stigma and the persons affected by stigma. Even when used on a single level, there is evidence that using multiple interventions is more effective than using a single intervention [111].

In contrast to the use of instruments, certain interventions can even be used across multiple conditions simultaneously. This is the case for counselling services, skills-building, and economic empowerment programs and SHGs, for example.

One major problem is that funders of stigma reduction programs usually only fund condition-specific studies, measures, and interventions. Surveillance for stigma and stigma-mitigating interventions can be integrated in regular health and social services using generic tools and interventions. For example, in China, a stigma-reduction intervention focused on infection control through education and providing adequate supplies for practicing universal precautions [78, 129]. Similarly, in Vietnam, a 
Table 4 Interventions used across conditions to address internalized, anticipated, or experienced stigma or disclosure concerns among persons with the condition

\begin{tabular}{llll}
\hline Author Country & Condition Target group $N$ Evidence of effectiveness
\end{tabular}

\begin{tabular}{|c|c|c|c|c|}
\hline \multicolumn{5}{|c|}{ (Peer) counselling/education } \\
\hline $\begin{array}{l}\text { Nuwaha } \\
\text { et al. [115] }\end{array}$ & Uganda & HIV & $\begin{array}{l}\text { Adults in the } \\
\text { community }\end{array}$ & $\begin{array}{l}1402 \text { before; } \\
1562 \text { after }\end{array}$ \\
\hline
\end{tabular}

\begin{tabular}{|c|c|c|c|}
\hline $\begin{array}{l}\text { Jürgensen } \\
\text { et al. [116] }\end{array}$ & Zambia & HIV & $\begin{array}{l}\text { Adult } 16 \\
\text { and above }\end{array}$ \\
\hline
\end{tabular}

\begin{tabular}{|c|c|c|c|c|}
\hline $\begin{array}{l}\text { Conner } \\
\text { et al. [117] }\end{array}$ & USA & $\begin{array}{l}\text { Mental } \\
\text { illness }\end{array}$ & $\begin{array}{l}\text { Older adults with } \\
\text { depression } \\
\text { in community }\end{array}$ & 19 \\
\hline $\begin{array}{l}\text { Lusli } \\
\text { et al. [82] }\end{array}$ & Indonesia & Leprosy & $\begin{array}{l}\text { Persons affected } \\
\text { by leprosy }\end{array}$ & $\begin{array}{l}67 \text { clients; } \\
57 \text { controls }\end{array}$ \\
\hline
\end{tabular}

Skills building and empowerment

Cross \&

[76]

$\begin{array}{llll}\begin{array}{l}\text { Bellamy \& } \\ \text { Mowbray [119] }\end{array} & \text { USA } & \begin{array}{l}\text { Mental } \\ \text { health } \\ \text { conditions }\end{array} & \begin{array}{l}\text { Adults with } \\ \text { mental illness }\end{array} \\ & & & \\ \text { Dalal [72] } & \text { India } & \text { Disabilities } & \begin{array}{l}\text { Persons with } \\ \text { disabilities }\end{array}\end{array}$
by leprosy
The proportion of people who had ever tested for HIV increased from $18.6 \%$ to $62 \%(p<0.001)$. Among people who had ever tested, the proportion who disclosed their HIV test result to a sexual partner increased from $41 \%$ to $57 \%$

$(p<0.001)$. The proportion who wanted the infection status of a family member not to be revealed decreased from $68 \%$ to $57 \%(p<0.001)$

There was an overall reduction of $7 \%$ in stigma from baseline to follow-up, mainly due to a reduction in individual stigmatizing attitudes but not in per ceived stigma; the reduction did not differ between the trial arms $(p=0.423)$ Being tested for HIV was associated with a reduction in stigma $(p=0.030)$ and HBVCT had a larger impact on stigma than other testing approaches ( $p=0.080$ vs. $p=0.551$ )

ISMI scores significantly reduced after participating in the 3-month peer educator intervention

Significant reduction was observed between the before and after total SARI Stigma scale scores (mean difference clients 9.6 vs. 5.6 for controls),

Participation scale scores (mean difference clients 3.7 vs. 1.4 for controls) and WHOQOL-BREF scores (mean differ ence clients +6.5 vs. -2.0 for controls)

Leprosy Persons affected 152 SHG participants Social participation in the intervention and 102 controls group (where participants were working as change agents) was much better than in the control group; the median scores on the Participation scale were 0 and 7 , respectively $(p<0.0001$, Kruskal-Wallis test)

After a 6-month follow-up, those with greater participation showed greater quality of life, empowerment, school/vo cational enrollment, and encouragement from mental health workers; a significant condition effect was found for empower ment $(p<0.01)$ and for school efficacy $(p<0.05)$; at 12-month follow-up, college or vocational enrollment had increased significantly

The project resulted in four types of outcomes: (1) increased visibility and participation of people with disabilities in community activities; many of them stepped out of their houses for the first time; (2) the number of physically challenged attending meetings gradually increased from none to $30-40 \%$ during the 3 years; (3) there was almost a 150\% increase in immunization against polio in the third year; (4) a greater number of people were reaching out to hospitals and rehabilitation centers in a nearby city; people who earlier thought that nothing could be done were now exploring the possibilities of medical rehabilitation with community support
This concerned home-based counselling and testing program

HBVCT trial

Outcome assessed on average $1-1.5$ years after baseline 
Table 4 Interventions used across conditions to address internalized, anticipated, or experienced stigma or disclosure concerns among persons with the condition (Continued)

\begin{tabular}{|c|c|c|c|c|c|c|}
\hline Author & Country & Condition & Target group & $N$ & Evidence of effectiveness & Comments \\
\hline $\begin{array}{l}\text { Uys et al. } \\
{[71]}\end{array}$ & $\begin{array}{l}\text { Lesotho, Malawi, } \\
\text { South } \\
\text { Africa, Swaziland, } \\
\text { Tanzania }\end{array}$ & HIV & $\begin{array}{l}\text { Nurses } \\
\text { PLHA }\end{array}$ & $\begin{array}{l}41 \text { PLHA } \\
134 \text { nurses }\end{array}$ & $\begin{array}{l}\text { PLHA involved in the intervention } \\
\text { teams reported less stigma and increased } \\
\text { self-esteem Nurses in the intervention } \\
\text { teams and those in the target group } \\
\text { reported no reduction in stigma } \\
\text { or increases in self-esteem and self-efficacy, } \\
\text { but their HIV testing behavior increased } \\
\text { significantly }\end{array}$ & $\begin{array}{l}\text { Pre- and post-test measured } \\
\text { stigma, self-esteem and self- } \\
\text { efficacy; the post-test was con- } \\
\text { ducted within } 1 \text { month after } \\
\text { the intervention }\end{array}$ \\
\hline $\begin{array}{l}\text { Dadun et al. [85] } \\
\text { Dadun } \\
\text { et al. (submitted) }\end{array}$ & Indonesia & Leprosy & $\begin{array}{l}\text { Persons affected } \\
\text { by leprosy }\end{array}$ & $\begin{array}{l}20 \text { qualitative }+30 \\
\text { quantitative }\end{array}$ & $\begin{array}{l}\text { In qualitative interviews, clients reported } \\
\text { growing businesses, better self-esteem, } \\
\text { improved interaction with neighbor and } \\
\text { most also less stigma than before; in some } \\
\text { cases, disclosure concern remained high; } \\
\text { in the quantitative interviews, the mean } \\
\text { difference between the pre- and } \\
\text { post-assessment total score of the SARI } \\
\text { Stigma scale for socioeconomic } \\
\text { development clients and the control } \\
\text { group was } 10.0 \text { vs. } 6.7, \text { for the } \\
\text { Participation scale } 3.6 \text { vs. } 1.4 \text { and for } \\
\text { the WHOQOL-BREF }+4.32 \text { vs. }-2.00\end{array}$ & $\begin{array}{l}\text { Outcome assessed on average } \\
1-1.5 \text { years after baseline }\end{array}$ \\
\hline
\end{tabular}

ISMI Internalized Stigma of Mental Illness, HBVCT home-based counselling and testing, PLHA people living with HIV and AIDS, SHG self-help group, WHOQOL-BREF WHO Quality of Life scale - Brief

stigma-reduction intervention allowed healthcare facility staff to develop practical skills around infection prevention and a code of practice, tailored for their own hospital's needs, on implementing stigma-free practices and universal precautions [130]. In the field of leprosy, counselling to mitigate the effects of stigma has been integrated in a range of hospitals that offer leprosy services in Nepal and India [131, 132].

Using generic tools and interventions within the health services would help overcome the siloed approach by demonstrating the advantages of integration, while simultaneously contributing to health systems strengthening. Dr Gottfried Hirnschall, WHO HIV Director, said, "We need to ensure that frontline health workers have the information and skills required to effectively identify, address and avoid stigma and discrimination of all types, including those related to HIV". ${ }^{1}$ Developing generic health-related stigma assessment and monitoring tools as well as generic stigma interventions would provide essential building blocks for making this possible.

\section{Limitations}

A limitation of this paper is that it is not based on a systematic literature review. We can therefore make no claim to completeness of the evidence to support the concept of health-related stigma. However, we believe that the cross-condition use of each instrument and intervention has been adequately demonstrated through our use of these selective, illustrative examples.

\section{Conclusions}

- Researchers, research funders, public health and social services managers, and health and social services practitioners should adopt cross-cutting, more cost-effective approaches to health-related stigma, seeking to use generic instruments and interventions where possible.

- Stigma studies should demonstrate how stigma theory and frameworks apply across conditions and delineate commonalities, as well as conditionspecific exceptions that might be important for understanding, measurement, or interventions.

- Researchers studying stigma should approach the issues more generically, adapting (potentially) generic stigma instruments to containing an optimal common core of items, identifying, where necessary, condition-specific add-on items or modules.

- Stigma studies should be commissioned to demonstrate the advantages and effectiveness of cross-condition approaches to measurement and interventions.

\section{Endnotes}

${ }^{1}$ http://www.who.int/mediacentre/commentaries/zerodiscrimination-day/en/; Accessed 13 June 2018

\footnotetext{
Abbreviations

CSS: Community Stigma Scale; EMIC: Explanatory Model Interview Catalogue; ISMI: Internalized Stigma of Mental IIIness; PLHIV: People living with HIV; POLs: Popular opinion leaders; SDS: Social Distance Scale; SHG: Self-help group; TB: Tuberculosis; WHOQOL-BREF: WHO Quality of Life scale
}

\section{Acknowledgements}

This article is part of a collection that draws upon a 2017 workshop on stigma research and global health, which was organized by the Fogarty International Center, National Institute of Health, United States. The article was supported by a generous contribution by the Fogarty International Center. We are grateful to Sarah Murray for proofreading the manuscript and for her encouragement during the writing of the paper. 


\section{Funding}

The authors were supported by their respective organizations and institutes, but other than the support of the Fogarty International Center mentioned below, no additional funding was involved in this study. WvB was supported by NLR and BAK is supported by the U.S. National Institutes of Health (K01MH104310; R21MH111280). LN is supported by RTI International.

\section{Availability of data and materials}

All data contained in this paper has been previously published elsewhere.

\section{Authors' contributions}

WvB was the main author of the paper. JC, SG, BK, LN, MS, EW, and LY contributed to and/or commented on the content of the paper. All authors read and approved the final manuscript.

\section{Ethics approval and consent to participate}

Not applicable.

\section{Consent for publication}

All authors have read the manuscript and consented its publication.

\section{Competing interests}

The authors declare that they have no competing interests.

\section{Publisher's Note}

Springer Nature remains neutral with regard to jurisdictional claims in published maps and institutional affiliations.

\section{Author details}

${ }^{1}$ NLR, Wibautstraat 137k, 1097DN Amsterdam, Netherlands. ${ }^{2}$ Department of Physiological Nursing, Center for Tobacco Control Research and Education, University of California San Francisco, 2 Koret Way, San Francisco, CA 94143-0610, USA. ³ Department of Psychiatry, PGIMER, Chandigarh, India. ${ }^{4}$ Department of Psychiatry and Behavioral Sciences, George Washington University, Washington, DC, USA. ${ }^{5}$ RTI International, Washington, DC, USA ${ }^{6}$ Epidemiology Department, UNC Gillings School of Global Public Health, Chapel Hill, NC, USA. ${ }^{7}$ Centre for Longitudinal \& Life Course Studies, University of Antwerp, Antwerp, Belgium. ${ }^{8}$ Centre for Health Systems Research \& Development, University of the Free State, Bloemfontein, South Africa. ${ }^{9}$ College of Global Public Health, New York University, New York, NY, USA. ${ }^{10}$ Mailman School of Public Health, Columbia University, New York, NY, USA.

Received: 13 June 2018 Accepted: 18 December 2018

Published online: 15 February 2019

\section{References}

1. Jones EE, Edward E, Farina A, Hasdorf A, Markus H, Miller DT, Scott R. Social stigma: the psychology of marked relationships. New York: W.H. Freeman; 1984.

2. Sharac J, McCrone P, Clement S, Thornicroft G. The economic impact of mental health stigma and discrimination: a systematic review. Epidemiol Psichiatr Soc. 2010;19:223-32.

3. van Brakel WH. Measuring health-related stigma-A literature review. Psychol Health Med. 2006;11:307-34.

4. Seroalo KB, Du Plessis E, Koen MP, Koen V. A critical synthesis of interventions to reduce stigma attached to mental illness. Heal SA Gesondheid. 2014:19.

5. Weiss MG. Stigma and the social burden of neglected tropical diseases. PLoS Negl Trop Dis. 2008;2:e237.

6. Pescosolido BA, Medina TR, Martin JK, Long JS. The "backbone" of stigma: Identifying the Global core of public prejudice associated with mental illness. Am J Public Health. 2013:103:853-60.

7. Parker R, Aggleton P. HIV and AIDS-related stigma and discrimination: a conceptual framework and implications for action. Soc Sci Med. 2003:57:13-24.

8. Ogden J, Nyblade L. Common at Its Core: HIV-Related Stigma; 2005.

9. Pescosolido BA, Martin JK. The Stigma Complex. Annu Rev Sociol. 2015;41: 87-116.

10. Hofstraat $K$, van Brakel WH. Social stigma towards neglected tropical diseases: a systematic review. Int Health. 2016;8(suppl 1):153-70.
11. Heijnders ML, Van der Meij S. The fight against stigma: an overview of stigma-reduction strategies and interventions. Psychol Health Med. 2006;11: 353-63.

12. Cross HA, Heijnders ML, Dalal A, Sermrittirong S, Mak S. Interventions for Stigma Reduction - Part 2: Practical Applications. Disabil CBR Incl Dev. 2012 22:71-80.

13. Boyd JE, Adler EP, Otilingam PG, Peters T. Internalized Stigma of Mental IIIness (ISMI) scale: a multinational review. Compr Psychiatry. 2014;55:221-31.

14. Scambler G. Stigma and disease: Changing paradigms. Lancet. 1998:352:1054-5.

15. Scambler G. Re-framing Stigma: Felt and Enacted Stigma and Challenges to the Sociology of Chronic and Disabling Conditions. Soc Theory Heal. 2004;2: 29-46.

16. Link BG, Phelan JC. Conceptualizing Stigma. Annu Rev Sociol. 2001;27:363-85.

17. Pescosolido BA, Martin JK, Lang A, Olafsdottir S. Rethinking theoretical approaches to stigma: A Framework Integrating Normative Influences on Stigma (FINIS). Soc Sci Med. 2008;67:431-40

18. Marlow LAV, Waller J, Wardle J. Variation in blame attributions across different cancer types. Cancer Epidemiol Biomarkers Prev. 2010;19:1799-805.

19. Weiss MG, Ramakrishna J, Somma D. Health-related stigma: rethinking concepts and interventions. PsycholHealth Med. 2006;11:277-87.

20. Scambler G. Health-related stigma. Sociol Health IIIn. 2009:31:441-55.

21. Cataldo JK, Slaughter R, Jahan TM, Pongquan VL, Hwang WJ. Measuring Stigma in People With Lung Cancer: Psychometric Testing of the Cataldo Lung Cancer Stigma Scale. Oncol Nurs Forum. 2011;38:E46-54.

22. Weiss MG, Ramakrishna J. Stigma interventions and research for international health. Lancet. 2006;367:536-8.

23. Major B, O'Brien LT. The Social Psychology of Stigma. Annu Rev Psychol. 2005:56:393-421.

24. Berger BE, Ferrans CE, Lashley FR. Measuring stigma in people with HIV: psychometric assessment of the HIV stigma scale. Res Nurs Health. 2001;24: 518-29.

25. Kalichman SC, Ramachandran B, Catz S. Adherence to combination antiretroviral therapies in HIV patients of low health literacy. J Gen Intern Med. 1999:14:267-73.

26. Ablon J. The nature of stigma and medical conditions. Epilepsy Behav. 2002 3:2-9.

27. Fife BL, Wright ER. The Dimensionality of Stigma: A Comparison of Its Impact on the Self of Persons with HIV/AIDS and Cancer. J Health Soc Behav. 2000;41:50

28. Nyblade L. Measuring HIV stigma: existing knowledge and gaps. Psychol Health Med. 2006;11:335-45

29. Gebremariam MK, Bjune GA, Frich JC. Barriers and facilitators of adherence to TB treatment in patients on concomitant TB and HIV treatment: a qualitative study. BMC Public Health. 2010;10:651.

30. Katz IT, Ryu AE, Onuegbu AG, Psaros C, Weiser SD, Bangsberg DR, et al. Impact of HIV-related stigma on treatment adherence: systematic review and metasynthesis. Journal of the International AIDS Society. 2013;16(3 Suppl 2).

31. Heijnders ML. Experiencing leprosy: perceiving and coping with leprosy and its treatment. A qualitative study conducted in Nepal. LeprRev. 2004;75:327-37.

32. Meima A, Saunderson PR, Gebre S, Desta K, van Oortmarssen GJ, Habbema JD. Factors associated with impairments in new leprosy patients: the AMFES cohort. Lepr Rev. 1999;70:189-203.

33. Van Veen $\mathrm{NH}$, Meima A, Richardus JH. The relationship between detection delay and impairment in leprosy control: a comparison of patient cohorts from Bangladesh and Ethiopia. Lepr Rev. 2006:77:356-65.

34. Ramadhani HO, Thielman NM, Landman KZ, Ndosi EM, Gao F, Kirchherr JL, et al. Predictors of Incomplete Adherence, Virologic Failure, and Antiviral Drug Resistance among HIV-Infected Adults Receiving Antiretroviral Therapy in Tanzania. Clin Infect Dis. 2007:45:1492-8.

35. Link BG, Mirotznik J, Cullen FT. The Effectiveness of Stigma Coping Orientations: Can Negative Consequences of Mental Illness Labeling be Avoided? J Health Soc Behav. 1991;32:302.

36. Link BG, Struening EL, Neese-Todd S, Asmussen S, Phelan JC. On Describing and Seeking to Change the Experience of Stigma. Psychiatr Rehabil Ski. 2002;6:201-31

37. Clement S, Schauman O, Graham T, Maggioni F, Evans-Lacko S, Bezborodovs $\mathrm{N}$, et al. What is the impact of mental health-related stigma on help-seeking? A systematic review of quantitative and qualitative studies. Psychological Medicine. 2015;45:11-27.

38. Nyblade L, Stangl A, Weiss E, Ashburn K. Combating HIV stigma in health care settings: What works? J Int AIDS Soc. 2009;12:15. 
39. Rueda S, Mitra S, Chen S, Gogolishvili D, Globerman J, Chambers L, et al. Examining the associations between HIV-related stigma and health outcomes in people living with HIV/AIDS: a series of meta-analyses. BMJ Open. 2016;6:e011453.

40. Sermrittirong $\mathrm{S}$, van Brakel WH. How to reduce stigma in leprosy - a systematic literature review. Lepr Rev. 2014;85:149-57.

41. Link BG, Yang LH, Phelan JC, Collins PY. Measuring mental illness stigma. Schizophr Bull. 2004;30:511-41.

42. National Academies of Sciences Engineering and Medicine. Ending discrimination against people with mental and substance use disorders: the evidence for stigma change. Washington, D. C.: National Academies Press; 2016

43. Peters RMH, Dadun, Van Brakel WH, Zweekhorst MBM, Damayanti R, Bunders JFG, et al. The Cultural Validation of Two Scales to Assess Social Stigma in Leprosy. PLoS Negl Trop Dis. 2014;8.

44. Boyd-Ritsher J, Otilingam PG, Grajales M. Internalized stigma of mental illness: psychometric properties of a new measure. Psychiatry Res. 2003;121:31-49.

45. Weiss MG, Doongaji DR, Siddhartha S, Wypij D, Pathare S, Bhatawdekar M, et al. The Explanatory Model Interview Catalogue (EMIC). Contribution to cross-cultural research methods from a study of leprosy and mental health. BrJPsychiatry. 1992;160:819-30.

46. Bogardus ES. Measuring social distance. J Appl Sociol. 1925:299-308.

47. Parrillo VN, Donoghue C. Updating the Bogardus social distance studies: A new national survey. Soc Sci J. 2005:42:257-71.

48. Link BG. Understanding Labeling Effects in the Area of Mental Disorders: An Assessment of the Effects of Expectations of Rejection. Am Sociol Rev. 1987; $52: 96$

49. Chowdhury AN, Sanyal D, Bhattacharya A, Dutta SK, Banerjee S, De R, et al. Interrater reliability of the EMIC in a pilot field study in west Bengal. Int Med J. 2001:8:25-9.

50. Charles B, Jeyaseelan L, Pandian AK, Sam AE, Thenmozhi M, Jayaseelan V. Association between stigma, depression and quality of life of people living with HIV/AIDS (PLHA) in South India - a community based cross sectional study. BMC Public Health. 2012;12:463.

51. Quinn DM, Williams MK, Weisz BM. From discrimination to internalized mental illness stigma: The mediating roles of anticipated discrimination and anticipated stigma. Psychiatr Rehabil J. 2015;38:103-8.

52. Reinius M, Wettergren $L$, Wiklander M, Svedhem V, Ekström AM, Eriksson LE. Development of a 12-item short version of the HIV stigma scale. Health Qual Life Outcomes. 2017;15:115.

53. Rump B, De Boer M, Reis R, Wassenberg M, Van Steenbergen J. Signs of stigma and poor mental health among carriers of MRSA.J Hosp Infect. 2017;95:268-74

54. Boyd JE, Otilingam PG, DeForge BR. Brief Version of the Internalized Stigma of Mental IIness (ISMI) Scale: Psychometric Properties and Relationship to Depression, Self Esteem, Recovery Orientation, Empowerment. Psychiatr Rehabil J. 2014;37:17-23

55. Kalichman SC, Simbayi LC. HIV testing attitudes, AIDS stigm, and voluntary HIV counselling and testing in a black township in Cape Town, South Africa. Sex Transm Infect. 2003;79:442-7.

56. Brown W. Can social marketing approaches change community attitudes towards leprosy? Lepr Rev. 2006;77:89-98.

57. Cross HA, Heijnders ML, Dalal AK, Sermrittirong S, Mak S. Interventions for Stigma Reduction - Part 1: Theoretical Considerations. Disabil CBR Incl Dev. 2012;22.

58. Sengupta S, Banks B, Jonas D, Miles MS, Smith GC. HIV interventions to reduce HIV/AIDS stigma: A systematic review. AIDS and Behavior. 2011;15:1075-87.

59. Stangl AL, Lloyd JK, Brady LM, Holland CE, Baral S. A systematic review of interventions to reduce HIV-related stigma and discrimination from 2002 to 2013: how far have we come? J Int AIDS Soc. 2013;16(3 Suppl 2):18734.

60. Griffiths KM, Carron-Arthur B, Parsons A, Reid R. Effectiveness of programs for reducing the stigma associated with mental disorders. A meta-analysis of randomized controlled trials. World Psychiatry. 2014;13:161-75.

61. Sermrittirong $S$, van Brakel WH, Bunders JFG, Unarat G, Thanyakittikul P. The Effectiveness of De-stigmatising Interventions. Int J Trop Dis Heal. 2014;4: 1218-1232.

62. Thornicroft G, Mehta N, Clement S, Evans-Lacko S, Doherty M, Rose D, et al. Evidence for effective interventions to reduce mental-health-related stigma and discrimination. Lancet. 2016:387:1123-32

63. Sommerland N, Wouters E, Mitchell EMH, Ngicho M, Redwood L, Masquillier

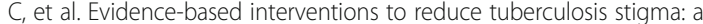
systematic review. Int J Tuberc Lung Dis. 2017;21:81-6.
64. McLeroy KR, Bibeau D, Steckler A, Glanz K. An Ecological Perspective on Health Promotion Programs. Health Educ Q. 1988;15:351-77.

65. Opala J, Boillot F. Leprosy among the Limba: illness and healing in the context of world view. Soc Sci Med. 1996:42:3-19.

66. Chen PC, Sim HC. The development of culture-specific health education packages to increase case-finding of leprosy in Sarawak. Southeast Asian J Trop Med Public Heal. 1986;17:427-32.

67. Thornicroft G, Brohan E, Kassam A, Lewis-Holmes E. Reducing stigma and discrimination: Candidate interventions. Int J Ment Health Syst. 2008;2:3.

68. Visschedijk J, van de Broek J, Eggens H, Lever P, van Beers S, Klatser P. Mycobacterium leprae--millennium resistant! Leprosy control on the threshold of a new era. Trop Med Int Health. 2000;5:388-399.

69. Williams PG, Dewapura D, Gunawardene P, Settinayake S. Social marketing to eliminate leprosy in Sri Lanka. Soc Mar Q. 1998;4:27-31.

70. Gussow Z, Tracy GS. Stigma and the leprosy phenomenon: the social history of a disease in the nineteenth and twentieth centuries. Bull Hist Med. 1970; 44:425.

71. Uys L, Chirwa M, Kohi T, Greeff M, Naidoo J, Makoae L, et al. Evaluation of a Health Setting-Based Stigma Intervention in Five African Countries. AIDS Patient Care STDS. 2009;23:1059-66.

72. Dalal AK. Social interventions to moderate discriminatory attitudes: the case of the physically challenged in India. PsycholHealth Med. 2006;11:374-82.

73. Bos AER, Schaalma HP, Pryor JB. Reducing AIDS-related stigma in developing countries: The importance of theory- and evidence-based interventions. Psychol Heal Med. 2008;13:450-60.

74. Peters RMH, Zweekhorst MBM, van Brakel WH, Bunders JFG, Irwanto. 'People like me don't make things like that': Participatory video as a method for reducing leprosy-related stigma. Glob Public Health. 2016;11:666-82.

75. Rogers EM. Diffusion of innovations. 5th ed. New York [etc.]: Free Press; 1983.

76. Cross HA, Choudhary RK. STEP an intervention to address the issue of stigma related to leprosy in Southern Nepal. Lepr Rev. 2005;76:316-24.

77. Young SD, Konda K, Caceres C, Galea J, Sung-Jae L, Salazar X, et al. Effect of a community popular opinion leader HIV/STI intervention on stigma in urban, coastal Peru. AIDS Behav. 2011;15:930-7.

78. Li L, Guan J, Liang LJ, Lin C, Wu Z. Popular opinion leader intervention for HIV stigma reduction in health care settings. AIDS Educ Prev. 2013;25:327-35.

79. Kelly JA. Popular opinion leaders and HIV prevention peer education: Resolving discrepant findings, and implications for the development of effective community programmes. AIDS Care - Psychol Socio-Medical Asp AIDS/HIV. 2004;16:139-50.

80. Sommerland N, Wouters E, Masquillier C, Engelbrecht M, Kigozi G, Uebel K, et al. Stigma as a barrier to the use of occupational health units for tuberculosis services in South Africa. Int J Tuberc Lung Dis. 2017;21:75-80.

81. Augustine V, Warne K, Ramakrishna J, Mbwambo J, Singh S, Yosep A, et al Counselling to reduce stigma. First ed. London/Amsterdam: International Federation of Anti-Leprosy Associations (ILEP) and Netherlands Leprosy Relief (NLR); 2011.

82. Lusli M, Peters RMH, Zweekhorst MBM, van Brakel WH, Seda FS, Bunders JFG, et al. Lay and peer counsellors to reduce leprosy-related stigma-lessons learnt in Cirebon. Indonesia. Lepr Rev. 2015;86.

83. Denison JA, Tsui S, Bratt J, Torpey K, Weaver MA, Kabaso M. Do peer educators make a difference? An evaluation of a youth-led HIV prevention model in Zambian Schools. Health Educ Res. 2012;27:237-47.

84. Ebenso B, Fashona A, Ayuba M, Idah M, Adeyemi G, S-Fada S. Impact of socioeconomic rehabilitation on leprosy stigma in Northern Nigeria: findings of a retrospective study. Asia Pacific Disabil Rehabil J. 2007;18:98-119.

85. Dadun, van Brakel WH, Peters RMH, Lusli M, Zweekhorst MBM, Bunders JFG, et al. Impact of socio-economic development, contact and peer counselling on stigma against persons affected by leprosy in Cirebon, Indonesia - a randomised controlled trial. Lepr Rev. 2017;88:2-22.

86. Ebenso B, Ayuba M. "Money is the vehicle of interaction": insight into social integration of people affected by leprosy in northern Nigeria. Lepr Rev. 2010;81:99-110

87. Benbow C, Tamiru T. The experience of self-care groups with people affected by leprosy: ALERT, Ethiopia. Lepr Rev. 2001;72:311-21.

88. Velema JP, Ebenso B, Fuzikawa PL. Evidence for the effectiveness of rehabilitation-in-the-community programmes. Lepr Rev. 2008;79:65-82.

89. Thomas M, Thomas MJ. Self-help groups as a tool for economic empowerment of persons with disability. Asia Pacific Disabil Rehabil J. 2005.

90. Link BG, Cullen FT, Frank J, Wozniak JF. The Social Rejection of Former Mental Patients: Understanding Why Labels Matter. Am J Sociol. 1987;92:1461-500. 
91. Lee MY, Campbell AR, Mulford CL. Victim-blaming tendency toward people with aids among college students. J Soc Psychol. 1999;139:300-8.

92. Sikorski C, Luppa M, Angermeyer MC, Schomerus G, Link BG, Riedel-Heller SG. The association of BMI and social distance towards obese individuals is mediated by sympathy and understanding. Soc Sci Med. 2015;128:25-30.

93. Vlassoff C, Weiss MG, Ovuga EBL, Eneanya C, Nwel PT, Babalola SS, et al. Gender and the stigma of onchocercal skin disease in Africa. Soc Sci Med. 2000;50:1353-68.

94. Stienstra Y, van der Graaf WT, Asamoa K, van der Werf TS. Beliefs and attitudes toward Buruli ulcer in Ghana. Am J Trop Med Hyg. 2002;67:207-13.

95. Sermrittirong S, van Brakel WH, Kraipui N, Traithip S, Bunders JFG. Comparing the perception of community members towards leprosy and tuberculosis stigmatization. Lepr Rev. 2015;86:54-61.

96. Rensen C, Bandyopadhyay S, Gopal PK, van Brakel WH. Measuring leprosyrelated stigma - A pilot study to validate a toolkit of instruments. Disabil Rehabil. 2011;33:711-9.

97. Kaehler N, Adhikari B, Raut S, Marahatta SB, Chapman RS. Perceived Stigma towards Leprosy among Community Members Living Close to Nonsomboon Leprosy Colony in Thailand. PLoS One. 2015;10:e0129086.

98. Dadun, Peters RMH, van Brakel WH, Lusli M, Damayanti R, Bunders JFG, et al. Cultural validation of a new instrument to measure leprosy-related stigma: the SARI Stigma Scale. Lepr Rev. 2017;88:23-42.

99. Luoma JB, Kohlenberg BS, Hayes SC, Bunting K, Rye AK. Reducing self-stigma in substance abuse through acceptance and commitment therapy: Model, manual development, and pilot outcomes. Addict Res Theory. 2008;16:149-65.

100. Taft TH, Ballou S, Keefer L. A preliminary evaluation of internalized stigma and stigma resistance in inflammatory bowel disease. J Health Psychol. 2013;18:451-60

101. Stevelink SAM, van Brakel WH, Augustine V. Stigma and social participation in Southern India: Differences and commonalities among persons affected by leprosy and persons living with HIV/AIDS - PB - Routledge. Psychol Health Med. 2011;16:695-707.

102. Raguram R, Weiss MG, Channabasavanna SM, Devins GM. Stigma, depression, and somatization in South India. AmJPsychiatry. 1996;153:1043-9.

103. Raguram R, Raghu TM, Vounatsou P, Weiss MG. Schizophrenia and the cultural epidemiology of stigma in Bangalore, India. J Nerv Ment Dis. 2004; 192:734-44.

104. Grover S, Hazari N, Aneja J, Chakrabarti S, Avasthi A. Stigma and its correlates among patients with bipolar disorder: A study from a tertiary care hospital of North India. Psychiatry Res. 2016;244.

105. Brieger WR, Oshiname FO, Ososanya OO. Stigma associated with onchocercal skin disease among those affected near the Ofiki and Oyan Rivers in western Nigeria. Soc Sci Med. 1998;47:841-52.

106. Weiss MG, Auer C, Somma D, Abouihia A, Kemp J, Jawahar MS, et al. Gender and tuberculosis: Cross-site analysis and implications of a multicountry study in Bangladesh, India, Malawi; 2006. p. 2-100.

107. Masuda A, Hayes S, Fletcher L, Seignourel P, Bunting K, Herbst S, et al. Impact of acceptance and commitment therapy versus education on stigma toward people with psychological disorders 2 ? 45:2764-72.

108. Boulay M, Tweedie I, Fiagbey E. The effectiveness of a national communication campaign using religious leaders to reduce HIV-related stigma in Ghana. African J AIDS Res. 2008;7:133-41.

109. Peters RMH, Dadun, Zweekhorst MBM, Bunders JFG, Irwanto, van Brakel WH. A Cluster-Randomized Controlled Intervention Study to Assess the Effect of a Contact Intervention in Reducing Leprosy-Related Stigma in Indonesia. PLoS Negl Trop Dis. 2015;9.

110. Corrigan PW, Larson J, Sells M, Niessen N, Watson AC. Will filmed presentations of education and contact diminish mental illness stigma? Community Ment Health J. 2007:43:171-81.

111. Yiu JW, Mak WWS, Ho WS, Chui YY. Effectiveness of a knowledge-contact program in improving nursing students' attitudes and emotional competence in serving people living with HIV/AIDS. Soc Sci Med. 2010;71:38-44.

112. Couture S, Penn D. Interpersonal contact and the stigma of mental illness: A review of the literature. J Ment Heal. 2003;12:291-305.

113. Cross HA, Choudhary RK. Self care: a catalyst for community development. Asia Pacific Disabil Rehabil J. 2005;16:100-14.

114. Kelly JA, Murphy DA, Sikkema KJ, McAuliffe TL, Roffman RA, Solomon LJ, et al. Randomised, controlled, community-level HIV-prevention intervention for sexual-risk behaviour among homosexual men in US cities. Lancet. 1997; 350:1500-5.
115. Nuwaha F, Kasasa S, Wana G, Muganzi E, Tumwesigye E. Effect of homebased HIV counselling and testing on stigma and risky sexual behaviours: Serial cross-sectional studies in Uganda. J Int AIDS Soc. 2012;15.

116. Jürgensen M, Sandøy IF, Michelo C, Fylkesnes K. Effects of home-based Voluntary Counselling and Testing on HIV-related stigma: Findings from a cluster-randomized trial in Zambia. Soc Sci Med. 2013;81:18-25.

117. Conner O, McKinnon A, Ward J, Reynolds F, Brown C. Peer education as a strategy for reducing internalized stigma among depressed older adults. Psychiatr Rehabil J. 2015;38:186.

118. Lusli M, Peters R, van Brakel W, Zweekhorst M, lancu S, Bunders J, et al. The Impact of a Rights-Based Counselling Intervention to Reduce Stigma in People Affected by Leprosy in Indonesia. PLoS Negl Trop Dis. 2016;10.

119. Bellamy CD, Mowbray CT. Supported education as an empowerment intervention for people with mental illness. J Community Psychol. 1998;26: 401-13.

120. Pachankis JE, Hatzenbuehler ML, Wang K, Burton CL, Crawford FW, Phelan JC, et al. The Burden of Stigma on Health and Well-Being: A Taxonomy of Concealment, Course, Disruptiveness, Aesthetics, Origin, and Peril Across 93 Stigmas. Personal Soc Psychol Bull. 2018;44:451-74.

121. Logie CH, James L, Tharao W, Loutfy MR. HIV, gender, race, sexual orientation, and sex work: A qualitative study of intersectional stigma experienced by HIV-positive women in Ontario, Canada. PLoS Med. 2011;8: e1001124.

122. Ciftci A, Jones N, Corrigan PW. Mental Health Stigma in the Muslim Community. J Muslim Ment Health. 2013;7.

123. Earnshaw VA, Smith LR, Cunningham CO, Copenhaver MM. Intersectionality of internalized HIV stigma and internalized substance use stigma: Implications for depressive symptoms. J Health Psychol. 2015;20:1083-9.

124. Van Rie A, Sengupta S, Pungrassami P, Balthip Q, Choonuan S, Kasetjaroen $Y$, et al. Measuring stigma associated with tuberculosis and HIV/AIDS in southern Thailand: exploratory and confirmatory factor analyses of two new scales. TropMedIntHealth. 2008;13:21-30.

125. Wouters E, Rau A, Engelbrecht M, Uebel K, Siegel J, Masquillier C, et al. The Development and Piloting of Parallel Scales Measuring External and Internal HIV and Tuberculosis Stigma among Healthcare Workers in the Free State Province, South Africa. Clin Infect Dis. 2016;62(suppl 3):S244-54.

126. Mak WW, Mo PK, Cheung RY, Woo J, Cheung FM, Lee D. Comparative stigma of HIV/AIDS, SARS, and tuberculosis in Hong Kong. Soc Sci Med. 2006;63:1912-22.

127. van Brakel WH. Measuring Leprosy Stigma - A Preliminary Review of the Leprosy Literature. Int J Lepr Other Mycobact Dis. 2003;71.

128. Scambler $G$, Heijnders $M$, van Brakel WH. Understanding and tackling health-related stigma. Psychol Heal Med. 2006;11:269-70.

129. Li L, Liang LJ, Lin C, Wu Z. Addressing HIV stigma in protected medical settings. AIDS Care. 2015;27:1439-42.

130. Pulerwitz J, Oanh KTH, Akinwolemiwa D, Ashburn K, Nyblade L. Improving Hospital-Based Quality of Care by Reducing HIV-Related Stigma: Evaluation Results from Vietnam. AIDS Behav. 2015;19:246-56.

131. Floyd-Richard M, Gurung S. Stigma reduction through group counselling of persons affected by leprosy--a pilot study. Lepr Rev. 2000;71:499-504.

132. Augustine V, Longmore M, Ebenezer M, Richard J. Effectiveness of social skills training for reduction of self-perceived stigma in leprosy patients in rural India--a preliminary study. Lepr Rev. 2012;83:80-92.

133. Adhikari B, Shrestha K, Kaehler N, Raut S, Chapman SR. Community attitudes towards leprosy affected persons in Pokhara municipality of western Nepal. J Nepal Health Res Counc. 2013;11(25):264-8.

134. Brohan E, Gauci D, Sartorius N, Thornicroft G. Self-stigma, empowerment and perceived discrimination among people with bipolar disorder or depression in 13 European countries: the GAMIAN-Europe study. J Affect Disord. 2011;129:56-63.

135. Singh A, Grover S, Mattoo SK. Validation of Hindi version of internalized stigma of mental illness scale. Indian J Soc Psychiatry. 2016;32:104.

136. Arachchi MAJDM, Kumari AGD, Wickramasinghe R, Kuruppu NR, Madhavi AVP. Stigmatization in Leprosy: A descriptive study from patients' perspective in Sri Lanka. Sci Res J. 2017;V IX:10-3.

137. Paxton S. The impact of utilizing HIV-positive speakers in AIDS education. AIDS Educ Prev. 2002;14:282-94. 